\title{
Life-Cycle Performance of a Bridge Subjected to Multiple Heavy Vehicle Impacts
}

\author{
Maizuar
}

\author{
Department of Infrastructure Engineering, The University of Melbourne, \\ Melbourne, Australia \\ Department of Civil Engineering, University of Malikussaleh, Aceh, Indonesia
}

Lihai Zhang

Department of Infrastructure Engineering, The University of Melbourne, Melbourne, Australia

Russell Thompson

Department of Infrastructure Engineering, The University of Melbourne, Melbourne, Australia

Herman Fithra

Department of Civil Engineering, University of Malikussaleh, Aceh, Indonesia

\begin{abstract}
Purpose - The purpose of this study is to develop a numerical framework to predict the time-dependent probability of failure of a bridge subjected to multiple vehicle impacts. Specially, this study focuses on investigating the inter-relationship between changes in life-cycle parameters (e.g., damage size caused by vehicle impact, loss of initial structural capacity, and threshold intervention) and bridges probability of failure.

Design/Methodology/Approach - The numerical procedure using MATLAB program is developed to compute the probability failure of a bridge. First, the importance and characteristics of life-cycle analysis is described. Then, model for damage accumulation and life cycle as a result of heavy vehicle impacts is discussed. Finally, the probability of failure of a bridge subjected to vehicle impacts as a result of change in life-cycle parameters is presented.

Findings - The results of study show that damage size caused by both vehicle impacts and loss of initial structural capacity have a great impact on the long-term safety of bridges. In addition, the probability of failure of a bridge under different threshold limits indicates that the structural intervention (e.g., repair or maintenance) should be undertaken to extend the service life of a bridge.
\end{abstract}

The first author wishes to acknowledge Indonesian Endowment Fund for Education for the support.

(C) Maizuar, Lihai Zhang, Russell Thompson, Herman Fithra. Published in the Emerald Reach Proceedings Series. Published by Emerald Publishing Limited. This article is published under the Creative Commons Attribution (CC BY 4.0) licence. Anyone may reproduce, distribute, translate and create derivative works of this article (for both commercial and non-commercial purposes), subject to full attribution to the original publication and authors. The full terms of this licence may be seen at http://creativecommons.org/licences/by/4.0/legalcode 
Proceedings of MICoMS 2017
Research Limitations/Implications - The damage sizes caused by heavy vehicle impacts are based on simple assumptions. It is suggested that there would be a further study to estimate the magnitude of bridge damage as a result of vehicle impact using the full-scale impact test or computational simulation.

Practical Implications - This will allow much better predictions for residual life of bridges which could potentially be used to support decisions on health and maintenance of bridges.

Originality/Value - The life-cycle performance for assessing the time-dependent probability of failure of bridges subjected to multiple vehicle impact has not been fully discussed so far.

All papers within this proceedings volume have been peer reviewed by the scientific committee of the Malikussaleh International Conference on Multidisciplinary Studies (MICoMS 2017).

\section{Introduction}

Bridges are critical transportation infrastructure networks and often are subjected to heavy traffic loads, harsh environments, and accidental damage (Deco and Frangopol, 2013; Frangopol and Soliman, 2016). For example, some catastrophic failure of bridges occurs because of collision accidents between bridges and heavy vehicles (e.g., over 30 tons). As seen in Maitland Pedestrian Bridge, Australia, in 2009, the collision accident between a bridge and medium truck collapsed the bridge, four persons were injured, and the road was closed for four days (Greg, 2009). The risk of damage caused by vehicle impacts can be more vulnerable for ageing bridges with an increased traffic loading. Thus, the permanent degradation and frequent vehicle collision with bridge damage highlighted the importance of safety bridges and traffic system in metropolitan areas.

Life-cycle performance of a structure is directly affected by different deterioration mechanisms such as sudden damaging extreme events, progressive deterioration, or combination of both (Melchers et al., 2008; Iervolino et al., 2013). Vehicle collision with bridge can be described as an extreme event that occur randomly in time and cause sudden damage to bridge structure (e.g., bridge pier). Therefore, the life-cycle performance of a bridge caused by heavy vehicle impacts can be modeled as shock degradation.

In recent decades, extensive research has been performed to develop an analytical model for shock degradation (Nakagawa, 1976, 1985; Feldman, 1977; Barlow and Proschan, 1996). However, the majority of shock-based degradation and failure models developed mainly focus on earthquakes. Such application related to earthquake damage of structures can be found in the study of Rackwitz et al. (2005) and Sánchez-Silva and Rackwitz (2004). In addition, the combined effect of multiple deterioration mechanisms on structures (e.g., shock and progressive deterioration) has also been investigated (Yang and Klutke, 2000; SanchezSilva et al., 2011). However, highway bridges could also be subjected to accidental heavy vehicle impacts and their effects on damage accumulation have not been fully discussed in the literature so far. The purpose of this study is to develop a numerical framework to predict the time-dependent probability of failure of a bridge subjected to multiple vehicle impacts.

\subsection{Life-cycle performance of a bridge subjected to vehicle impacts}

The performance of a bridge system or a component throughout its lifetime subjected to multiple vehicle impacts can be represented by a general life-cycle model as shown in Figure 1. In a life-cycle model, the performance of a system is usually quantified in terms of structural capacity (e.g., material resistance and drift). The structural lifetime is defined as the length of time required by a structure to reach a predefined performance threshold values (e.g., $k^{*}$ and $s^{*}$ ). As shown in Figure 1, the threshold $k^{*}$ represents the minimum 


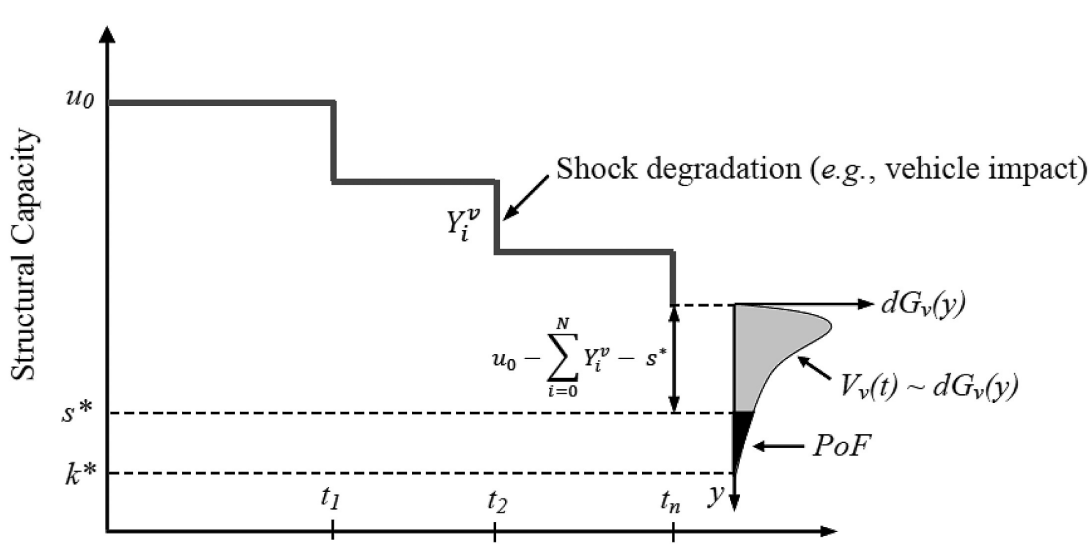

Time (t)
Life-Cycle

Performance

15

Figure 1.

Life-Cycle Model of a

Structure Subjected to Shock Events (e.g., Vehicle Impacts)

structural performance level while the threshold $s *$ denotes the ultimate structural capacity which refers to structural collapse.

In this study, the damage accumulation caused by heavy vehicle impacts and their occurrences was assumed to occur randomly over time with each truck impact resulting in a random reduction in structural capacity. Therefore, the structural damage of a bridge can be modeled using marked point process. Let us consider a structural system with an initial capacity $V_{O}$ as shown in Figure 1 . If the shock size $\left(Y_{i}^{v}\right)$ and the time interval between shocks $X=\Delta t_{i}^{v}$ are random variables, then the remaining capacity of the component at a particular time $V_{v}(t)$ can be computed as

$$
V_{v}(t)=V_{0}-D_{v}(t)-s^{*}
$$

where $s^{*}$ is the limit state design requirement of the bridge and $D_{v}(t)$ is the accumulated deterioration as a result of $N$ heavy truck impacts given by

$$
D_{v}(t)=\sum_{i=0}^{N} Y_{i}^{v}
$$

Then, the remaining structural capacity $V_{v}(t)$ can be rewritten as

$$
V_{v}(t)=V_{0}-\sum_{i=0}^{N} Y_{i}^{v}-s^{*}
$$

If distribution of $G_{v}(y)$ describes the probability of the bridge reaching a certain damage level as a result of vehicle impacts, then the probability of failure at a given time $P_{v}(t)$ is given by

$$
P_{v}(t)=1-\int_{0}^{V_{v}(t)} G_{v}(y) d y
$$

Assuming that the inter-arrival time of shocks $t_{i}^{v}$ and their sizes $Y_{i}^{v}$ are independent and identically distributed (iid) as well as exponentially distributed, a numerical procedure using 
Proceedings of MATLAB program was developed and the average values of the bridge probability of MICoMS 2017 failure were computed after 100 simulations.

\section{Case study}

The Montague Street Bridge located in South Melbourne, Australia, was used as a case study. This railway bridge has a length of $70 \mathrm{~m}$ and width of $7.5 \mathrm{~m}$. Information on vehicle collision with bridges in Melbourne Australia was based on "Crash Stats Data" provided by Data Victoria. Using exponential distribution, the inter-arrival heavy vehicle impacts was obtained statistically with the mean of 1.5 years. In this study, we assume the following:

- The initial structural capacity of the bridge $V_{0}$ is $100 \%$.

- The threshold intervention $s^{*}$ (i.e., limit state) is $30 \%$.

- The shock size (damage size) caused by a truck impact is exponentially distributed.

- The remaining structural capacity of the bridge $V_{v}(t)$ is exponentially distributed with a mean of 0.05 .

- Each vehicle impact on bridge is assumed to be statistically independent.

\section{Results and discussion}

The effect of three different mean damage sizes of the bridge caused by heavy vehicle impacts $\left(Y_{i}^{v}\right)$ (i.e., $2 \%, 3 \%$, and $5 \%$ ) on probability of failure of a bridge is shown in Figure 2. The results show that the increase in damage size caused by heavy vehicle impacts significantly increases the probability of failure and led to the decrease in the remaining service life of the bridge. Further, compared to the damage size of $2 \%$, the damage sizes of $3 \%$ and $5 \%$ could result in around $32 \%$ and $50 \%$ reduction in residual life of a bridge, respectively.

As deterioration increases, the structural capacity of a structure decreases. Figure 3 compares the probability of failure of the bridge under different initial structural capacities $u_{0}$ (i.e., $95 \%, 90 \%$, and $85 \%$ ). The results show that the loss of initial structural capacity could generally lead to the significant decrease of the probability of failure of the bridge.

Figure 2.

Probability of Failure of the Bridge under Different Damage Sizes

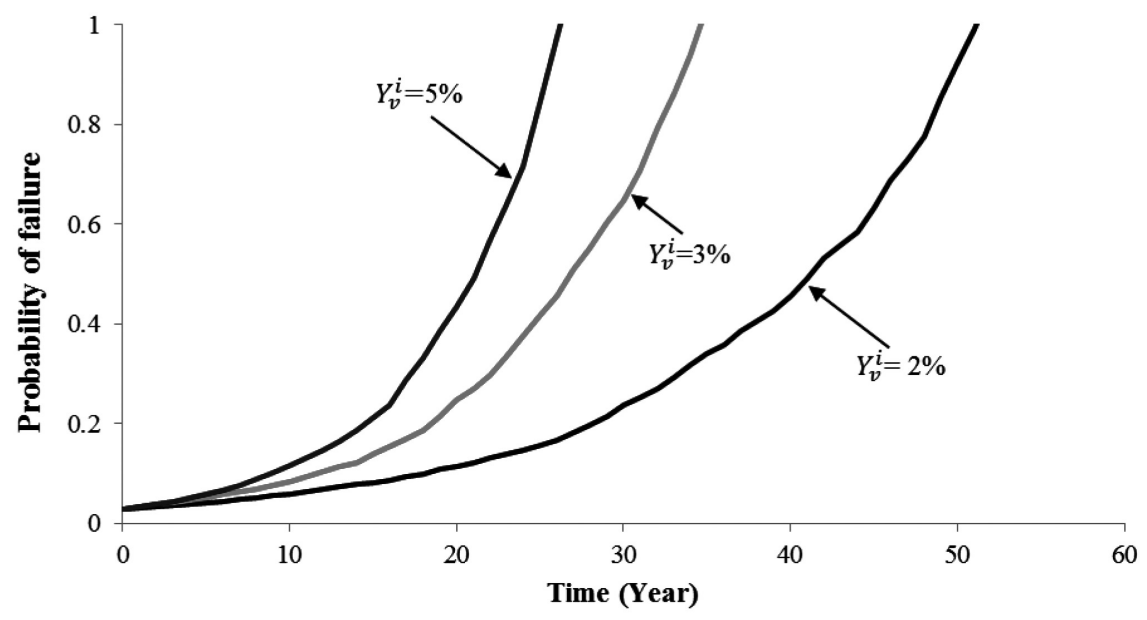




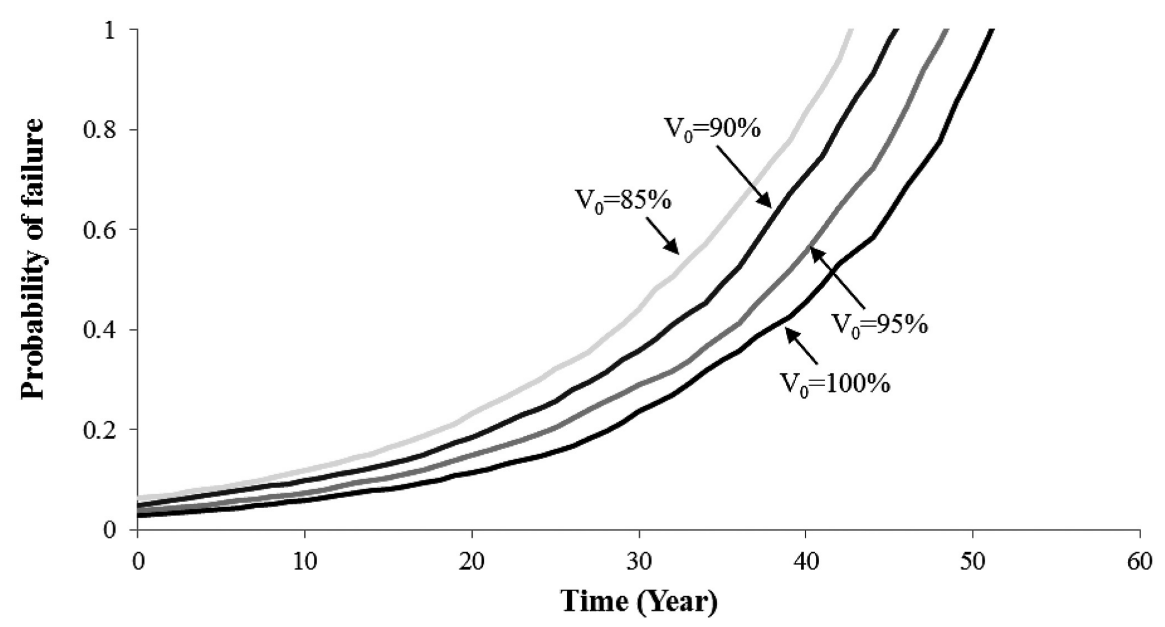

Life-Cycle
Performance

Figure 3.

Probability of Failure of the Bridge Under

Different Initial Structural Capacities

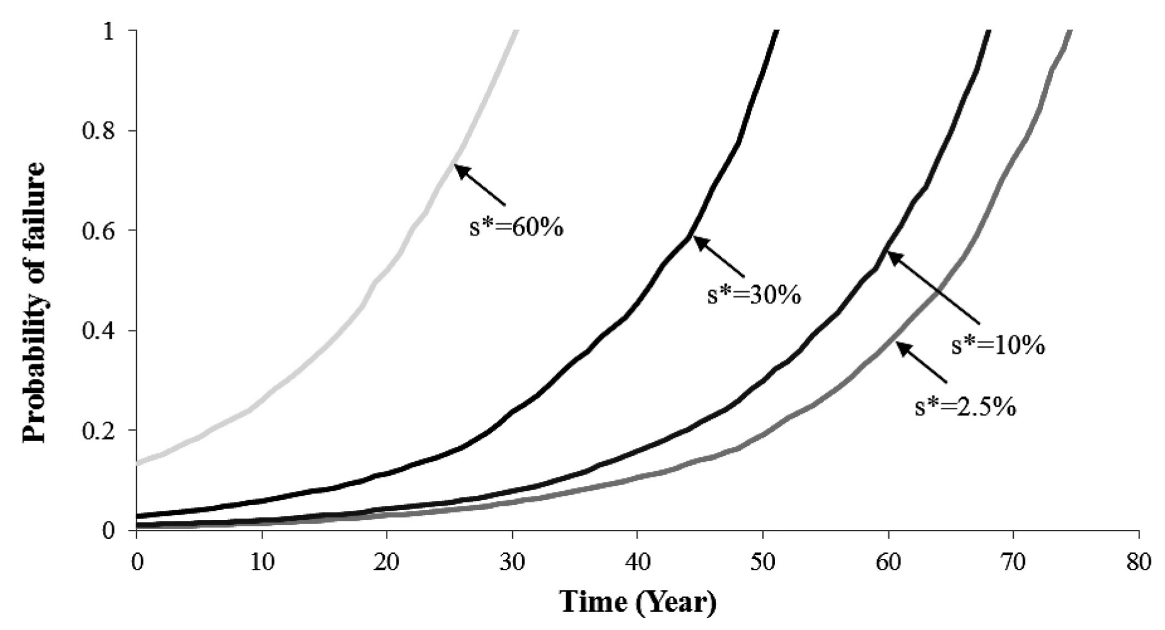

Figure 4.

Probability of Failure of the Bridge under Different Damage States

The threshold intervention $s^{*}$ describes the damage states of a bridge. Figure 4 shows the probability of failure of the bridge under different threshold intervention capacities (e.g., $2.5 \%, 10 \%, 30 \%$, and $60 \%$ ). The simulation results in Figure 4 show that the probability of failure of the bridge is larger for minor damage states and smaller for severe damages.

\section{Conclusion}

A life-cycle performance of a bridge subjected to multiple heavy vehicle impacts is presented. In particular, this study develops a numerical procedure for assessing the probability of failure of a bridge when both inter-arrival time of impacts and their sizes are random. First, the importance and characteristics of life cycle analysis is described. Then, model for damage accumulation and life cycle as a result of heavy vehicle impacts is 
Proceedings of MICoMS 2017 discussed. Finally, the probability of failure of a bridge subjected to vehicle impacts as a result of change in life-cycle parameters (e.g., damage size caused by vehicle impact and loss of initial structural capacity and threshold intervention) is presented. The outcomes of the study show that damage size caused by both vehicle impacts and loss of initial structural capacity has a significant effect on the residual life of bridges. In addition, the probability of failure of a bridge under different threshold limits is useful for making decisions related to structural maintenance or repair in the future.

\section{References}

Barlow, R.E. and Proschan, F. (1996). Mathematical Theory of Reliability, Society for Industrial and Applied Mathematics (SIAM), Philadelphia, PA.

Deco, A. and Frangopol, D.M. (2013). "Life-Cycle Risk Assessment of Spatially Distributed Aging Bridges Under Seismic and Traffic Hazards". Earthquake Spectra, Vol. 29, No. 1, pp. 127-154.

Feldman, R. (1977). "Optimal Replacement for Systems Governed by Markov Additive Shock Processes". The Annals of Probability, Vol. 5, No. 3, pp. 413-429.

Frangopol, D.M. and Soliman, M. (2016). "Life-Cycle of Structural Systems: Recent Achievements and Future Directions”. Structure \& Infrastructure Engineering: Maintenance, Management, LifeCycle Design \& Performance, Vol. 12, No. 1, pp. 1-20.

Greg, W. (2009). "Maitland Pedestrian Bridge Collapses on Highway". Available: http://www.theherald. com.au/story/494178/maitland-pedestrian-bridge-collapses-on-highway/ [acessed 22 December 2016].

Iervolino, I., Giorgio, M. and Chioccarelli, E. (2013). "Gamma Degradation Models for EarthquakeResistant Structures”. Structural Safety, Vol. 45, pp. 48-58.

Melchers, R.E., Li, C.Q. and Lawanwisut, W. (2008). "Probabilistic Modeling of Structural Deterioration of Reinforced Concrete Beams Under Saline Environment Corrosion". Structural Safety, Vol. 30, No. 5, pp. 447-460.

Nakagawa, T. (1976). "On a Replacement Problem of a Cumulative Damage Model”. Operational Research Quarterly, Vol. 27, No. 4, pp. 895-900.

Nakagawa, T. (1985). "Continuous and Discrete Age-Replacement Policies". The Journal of the Operational Research Society, Vol. 36, No. 2, pp. 147-154.

Rackwitz, R., Lentz, A. and Faber, M. (2005). "Socio-Economically Sustainable Civil Engineering Infrastructures by Optimization”. Structural Safety, Vol. 27, No. 3, pp. 187-229.

Sanchez-Silva, M., Klutke, G.-A. and Rosowsky, D.V. (2011). "Life-Cycle Performance of Structures Subject to Multiple Deterioration Mechanisms”. Structural Safety, Vol. 33, No. 3, pp. 206-217.

Sánchez-Silva, M. and Rackwitz, R. (2004). "Socioeconomic Implications of Life Quality Index in Design of Optimum Structures to Withstand Earthquakes”. Journal of Structural Engineering, Vol. 130, No. 6, pp. 969-977.

Yang, Y. and Klutke, G.-A. (2000). "Improved Inspection Schemes for Deteriorating Equipment". Probability in the Engineering and Informational Sciences, Vol. 14, No. 4, pp. 445-460.

\section{Corresponding author}

Maizuar can be contacted at maizuar@unimal.ac.id 


\section{University Library}

\section{- M M I N E R VA A gateway to Melbourne's research publications}

Minerva Access is the Institutional Repository of The University of Melbourne

Author/s:

Maizuar,;Zhang, L;Thompson, R;Fithra, $\mathrm{H}$

Title:

Life-cycle performance of a bridge subjected to multiple heavy vehicle impacts

Date:

2018-01-01

Citation:

Maizuar, , Zhang, L., Thompson, R. \& Fithra, H. (2018). Life-cycle performance of a bridge subjected to multiple heavy vehicle impacts. Emerald Reach Proceedings Series, 1 , pp.13-18. Emerald Publishing Limited.

Persistent Link:

http://hdl.handle.net/11343/268095

License:

CC BY 